\title{
Evaluation of anterior cruciate ligament reconstructed patients should include both self-evaluation and antero- posterior joint movement estimation?
}

\author{
Dario Santos ${ }^{1 *}$, Fernando Massa ${ }^{2}$ and Franco Simini ${ }^{3}$
}

*Correspondence: dsantos@hc.edu.uy

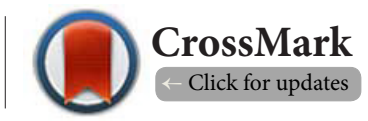

'Department of Rehabilitation, Clinical hospital, University of the Republic, Montevideo, Uruguay. ${ }^{2}$ Institute of Statistics, University of the Republic, Montevideo, Uruguay.

${ }^{3}$ Core Biomedical Engineering, Clinical hospital, University of the Republic, Montevideo, Uruguay.

\begin{abstract}
Background: The migration of the Tibio-femoral Contact Point of the Femur with respect to the tibial plateau is altered by the rupture of the Anterior Cruciate Ligament and again changed after reconstructive surgery, as shown by sequences of video fluoroscopic knee images during extension. Besides, subjective satisfaction of reconstructed knee function is assessed using the The Lysholm score and the Tegner activity scale. We have tested whether the subjective score is correlated to objective and dynamic joint anteroposterior movement after Anterior Cruciate Ligament reconstruction.

Methods: The Lysholm score and the Tegner activity scale was obtained by personal interviews and we have designed a new simple procedure (called CINARTRO) with interactive determination of Tibio-femoral Contact Point in each one of 30 video fluoroscopic images during extension to output clinical reports. Contact Point migration is expressed as percentage of tibial plateau length. We have applied the method to 5 male patients whose Tegner activity score was 7 (competitive amateur sportsmen) and 25 (SD 3.6) years old.
\end{abstract}

$\underline{\text { Results: }}$ Combination of subjective and clinical objective (quantitative \& dynamic) estimation of Tibiofemoral Contact Point migration showed no correlation in the 5 patients: $-0.46<\mathrm{r}<0.41,0.43<\mathrm{p}<0.87$ for neither injured nor reconstructed knee.

Conclusions: Due to the independence of subjective and objective dynamic evaluations of Anterior Cruciate Ligament reconstruction, both should be included to guide follow-up. This is because restricted Tibiofemoral Contact Point migration and eventually associated increased surface stress appear to have no subjective immediate consequences on patient comfort.

Keywords: ACL follow up, tibio-femoral contact point, lysholm score, tegner activity scale

\section{Introduction}

The knee joint is among the most often affected joints in the human body [1]. Anterior Cruciate Ligament (ACL) lesions account for $20 \%$ of knee lesions as a consequence of sports practice, as shown by epidemiological studies [2]. This yields an estimated 80,000 ACL lesions per year in the USA [3] and about $900 \mathrm{ACL}$ ruptures in three-Million people Uruguay [4]. Diagnostic tests to confirm ACL tears include the Lachman test, the pivot shift test and the use of the KT 1000/2000 arthrometer [5].
Magnetic resonance imaging is also used because it provides the fine soft tissue details necessary to confirm any diagnosis [6]. An ACL injury results in functional impairment of the knee [7] and of the overall lower limb function [8], which may lead to the indication of reconstructive surgery.

After surgery, rehabilitation takes approximately 6 months before close to normal activity is reached [9]. During this time, decisions are taken based on ongoing outcome measurements. These measurements are of great importance to help clinicians 
provide better information to their patients and to choose the best individualized management [10]. Laxity estimation for an injured knee can be performed by surgical navigation systems for $\mathrm{ACL}$ reconstruction, a complex procedure indeed for clinical decision making [11].

On one hand, quantitative methods to estimate the migration of the Tibio-femoral Contact Point (TFCP) are not used commonly in clinical practice, although they are considered highly objective and accurate $[12,13]$. TFCP methods are limited to biomechanics research settings [14]. The quantification of dynamic behaviour of the knee is of great importance to understand the effects of articular lesions, to evaluate the outcome of surgery as well as for follow up [15]. The fact that the TFCP studies include the function of the knee gives the dynamic quantification a clear superiority over the usual static methods such as the Lachmann test or the use of the arthrometer.

On the other hand, clinicians use subjective methods such as the Lysholm Score (LS) and the Tegner activity scale to record self assessed patient comfort $[16,17]$. Tegner activity level scale is used in conjunction with the Lysholm Knee Scale in patients with ACL injury [16]. Tegner Activity Scale is a graduated list of activities of daily living, recreation, and competitive sports. The patient is asked to select the level of participation that best describes their current level of activity and that before injury [18].

Sound clinical practice should include both subjective and objective evidence to better manage patients. The question arises when to ascertain any association between subjective and objective indicators, which could question the use of both indicators in case of full redundancy, or would stress the importance of using both, in case of complementarity. The data to be shown here look into this association by obtaining indicators by the two methods, and comparing them with by statistical analysis.

The purpose of this work is to verify whether there is any correlation between the subjective evaluation method used clinically described by Lysholm and Tegner $[19,20]$ and a kinematic approach to the knee function during active extensión. To this end we have developed a precise clinically compatible method and equipment based on ideas previously published $[15,21,22]$ and used only in research settings until today.

\section{Methods}

We have evaluated the $A C L$ reconstruction of five otherwise healthy subjects, after obtaining approval by the Ethics Committee of the Faculty of Medicine of Universidad de la Repùblica. Eligibility included a Tegner Activity Scale of 7 before injury. The complete evaluation was performed one week before surgery including a reference measurement on the contralateral knee and again six months after surgery. We have applied both the subjective and objective methods described: the Lysholm Score and the TFCP migration percentage. The age of the five male patients (all amateur sportsmen) was 25 (SD 3.6) years, BMI 23.2 (SD 1.8), all had an isolated tear of the $A C L$ and no ligament nor meniscal injury. $A C L$ injury was documented by MRI and clinical examination: positive Lachman, pivot shift and anterior drawer tests, all three tests performed by an expert orthopedic surgeon.

All patients had a healthy contralateral knee, confirmed by clinical examination. The first videofluoroscopic (VFC) exploration was done three months after injury, just one week before surgery (both injured and contralateral knees) and the second VFC exploration was performed six months after reconstruction and subsequent conventional rehabilitation $[\mathbf{9 , 2 3}]$. This second VFC was done only on the reconstructed knee.

$A C L$ reconstruction was performed by the technique known as "bone-patellar tendon-bone autograft". All five patients were evaluated and operated on by the same surgeon.

For a subjective measure, we chose the Lysholm Questionnaire Score which, acording to Risberg [24], is the most popular functional evaluation reported in the literature for knee reconstruction $[6,25]$. The LS represents the functional capacity of the knee, as felt by the patient, along the range of $0 \%$ to $100 \%$. The result is poor when $L S=65 \%$, from $66 \%$ to $83 \%$ intermediate, good from $84 \%$ to $94 \%$ and excellent above 95\% [26]. The LS was obtained for the 5 patients, before and after $\mathrm{ACL}$ reconstruction, at the same time the VFC imaging sessions were performed.

The patient is seated in such a way as to allow the knee joint to be imaged by the C-arm VFC. He is asked to raise $90^{\circ}$ the load-less leg in 2 seconds approximately from hanging to full extension.

To objectively determine the TFCP, we have used CINARTRO equipment which consists of a C-arm X-ray device with video data acquisition; hardware to digitize the images and a custom made software to calculate the percentage of migration of TFCP over the tibial plateau [4]. CINARTRO allows to measure the distance between the point of contact and the posterior tibial plateau extremity, for every VFC image in the three conditions (contralateral, injured and reconstructed) during a load-less active extension movement of the knee. Figure 2 shows one of the 30 images of VFC with the points marked by the user. The five points are selected by the operator of CINARTRO software intereactively, three along the condyle and two points at the tibial plateau extremities, as shown in Figure 1. The information of both segments (straight line for tibial plateau and three points curve for femur) is used to determine the TFCP acording to the Baltzopoulos method [13]. The projection of the TFCP on the tibial plateau segment is taken as percentage of the segment: e.g., a TFCP which project in the middle of the plateau is recorded as $50 \%$ in all subsequent analyses.

The measurements were taken on the VFC images by one operator, based on previous error methodology. The Baltzopoulos method originally estimated the error at less than $\mathbf{1 \%}[\mathbf{2 8 , 2 9}]$. Our own subsequent research published a similar figure of $2 \%$ [30]. Additionally the operator reliability coefficient 

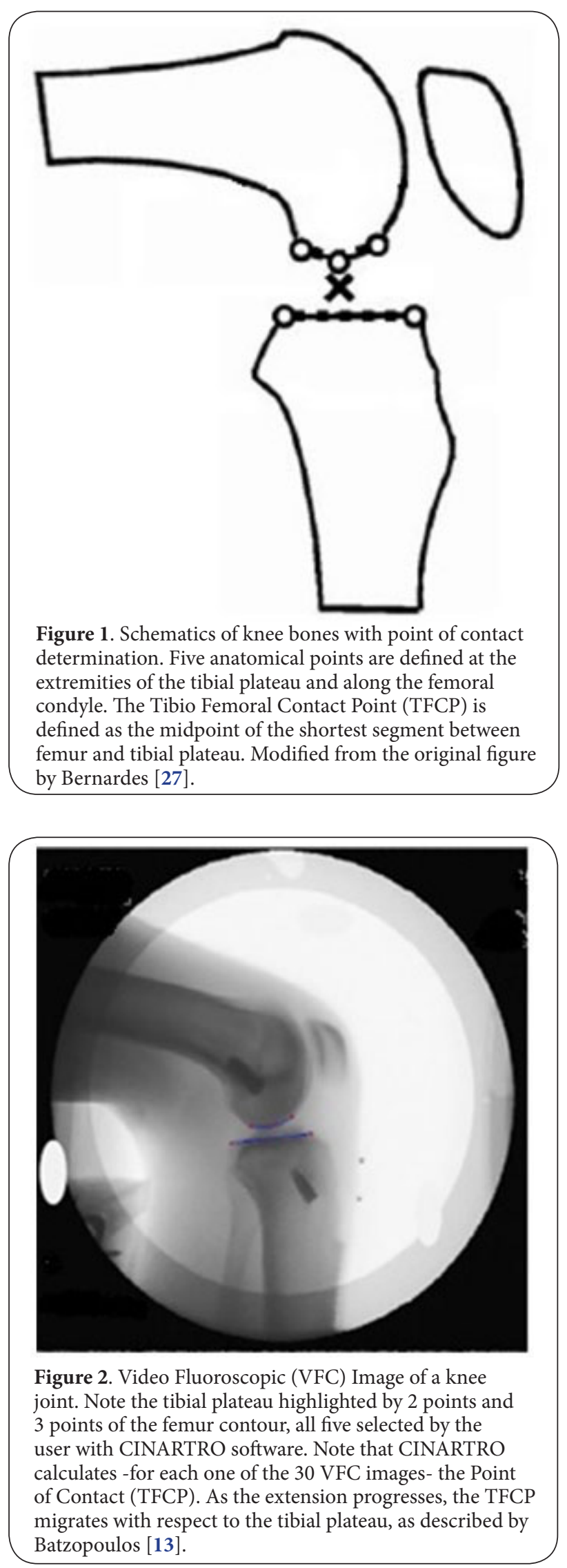

correlation [28] was calculated as $r=0.90$ referring to repeated measurements [30]. The association between subjective opinion and objective Tibio-femoral Contact Point (TFCP) was evaluated using Spearman's correlation coefficient [31].

The election of this particular index over Pearson's is because of the small sample size, situation in which non-parametric statistics tend to overperform their parametric counterparts. The inferential assessment of the estimations was carried out by means of Student's approximation with a 0.05 significance level.

\section{Results}

TFCP migration of healthy knees is $15 \%$ to $41 \%$ at $90^{\circ}$ flexion (beginning of movement, hanging leg) up to $46 \%$ to $66 \%$ at full extension. When the ACL tears, TFCP excursion is limited to $25 \%$ to $37 \%$ (hanging) and $49 \%$ to $60 \%$ at full extension. With a reconstructed ACL TFCP migration tends back to normal values, in our case $25 \%$ to $42 \%$ (hanging) up to $50 \%$ to $62 \%$ (extension), quite similar to previously published data [15].

Subjective score results are also shown in Table 1. A LS of 100 was assigned for the contralateral knee since all patients were amateur sportsmen, and therefore were normal. After injury and before reconstruction, LS was down to $44 \%$ to $65 \%$. After surgery, LS of $91 \%$ to $100 \%$ are almost back to normal.

The combination of subjective and objective measures is shown in Figure 3. For one, all contralateral knees are depicted

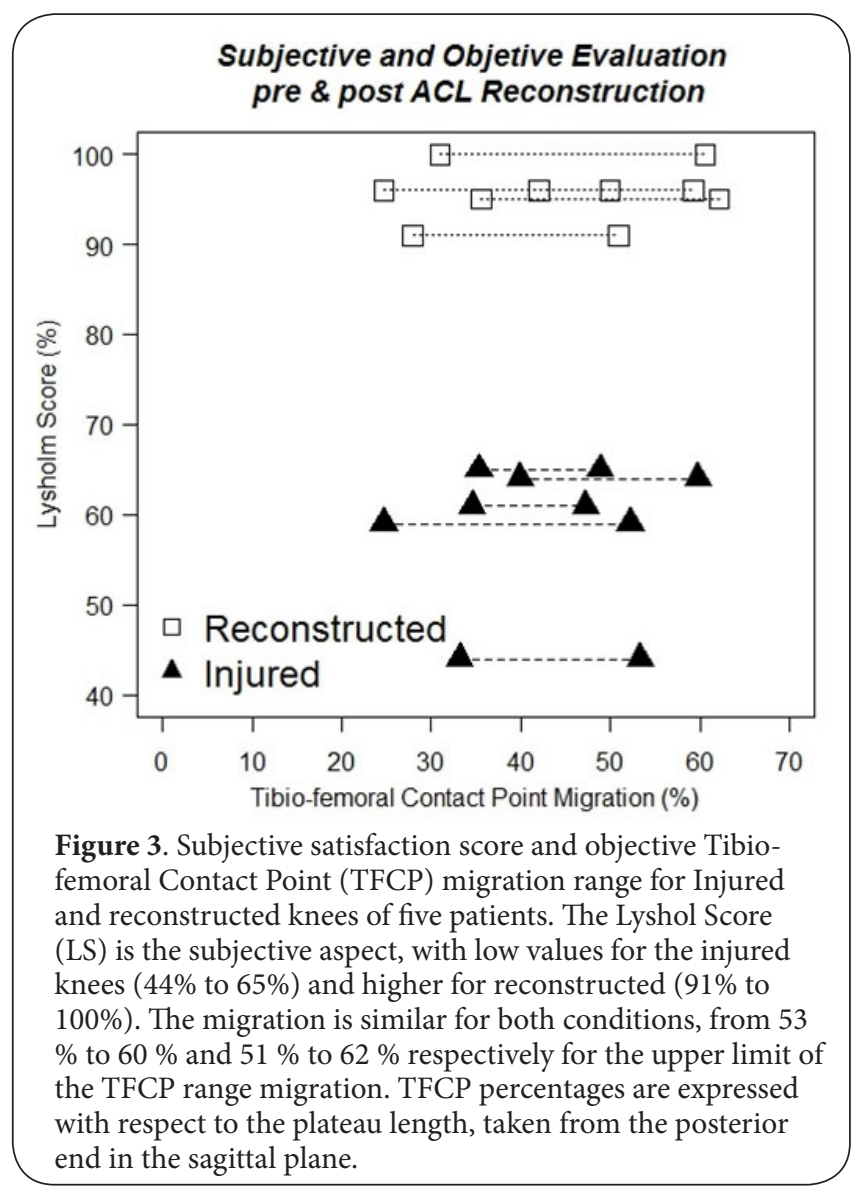


Santos et al. Physical Therapy and Rehabilitation 2015,

http://www.hoajonline.com/journals/pdf/2055-2386-2-3.pdf

doi: $10.7243 / 2055-2386-2-3$

Table 1. Combined subjective \& objetive evaluation of acl reconstruction: lysholm score and tfcp migration: healthy, injured and reconstructed knees.

\begin{tabular}{|c|c|c|c|c|c|c|c|c|c|c|c|}
\hline \multirow[b]{2}{*}{ Patient } & \multicolumn{4}{|c|}{ Healthy Knee \% } & \multicolumn{3}{|c|}{ Injured Knee \% } & \multicolumn{4}{|c|}{ Reconstructed Knee \% } \\
\hline & $\operatorname{minTFCP}{ }^{\star}$ & $\max \operatorname{TFCP}^{*}$ & TFCPrange & $\operatorname{minTFCP}$ & $\max$ TFCP & $\mathbf{L S}^{* *}$ & TFCPrange & $\min$ TFCP $^{\star}$ & $\max$ TFCP $^{*}$ & LS & TFCP range \\
\hline 1 & 25 & 49 & 24 & 33 & 53 & 44 & 20 & 28 & 51 & 91 & 23 \\
\hline 2 & 33 & 46 & 13 & 37 & 49 & 61 & 13 & 31 & 61 & 100 & 30 \\
\hline 3 & 38 & 56 & 18 & 35 & 49 & 65 & 14 & 36 & 62 & 95 & 27 \\
\hline 4 & 41 & 66 & 25 & 40 & 60 & 64 & 20 & 42 & 59 & 96 & 17 \\
\hline 5 & 15 & 49 & 34 & 25 & 52 & 59 & 28 & 25 & 50 & 96 & 25 \\
\hline $\begin{array}{l}\text { r maxTF- } \\
\text { CP-LTI } \\
\text { (P-value) }\end{array}$ & & & & & & & $\begin{array}{l}0.31 \\
0.61)\end{array}$ & & $\begin{array}{l}0.10 \\
(0.87)\end{array}$ & & \\
\hline $\begin{array}{l}\text { rTFCP-LTI } \\
\text { (P-value) }\end{array}$ & & & & & & & $\begin{array}{l}-0.46 \\
(0.43)\end{array}$ & & & & $\begin{array}{l}0.41 \\
(0.49)\end{array}$ \\
\hline
\end{tabular}

*TFCP: Tibio-femoral Contact Point as percentage of tibial plateau from back to front in sagittal plane as shown in Figure 1.

${ }^{* *}$ LS: Lysholm Score (\%).

by a $100 \%$ satisfaction. The same patients, who had a low $44 \%$ to $65 \%$ LS for injured knees, later refer scores of $91 \%$ to $100 \%$ after reconstruction, which is a success of surgery.

As Figure 3 shows, whatever the TFCP migration and its range with respect to the posterior tibial plateau extremity, subjective satisfaction depends solely upon whether the knee has a torn or reconstructed/intact ACL. There is little influence derived from a more or less knee joint looseness. Table 1 includes the correlation coefficient calculated for LS with respect to TFCP migration range and with respect to the end point of the migration.

There is no association between the two evaluation methods: subjective and objective. For healthy knee, there is no difference because all patients refer $100 \%$ satisfaction, while exhibiting small differences in TFCP migration. For injured knees, the coefficient of correlation (CC) is very small $(-0,308)$ and with a non significant $p$ value of 0.614 . For reconstructed knees $C C=0.102$ with a large $p$ value, which is interpreted as no correlation.

\section{Discussion and conclusion}

The objective knee TFCP migration figures are very much the same as those reported in the literature, such as by Dennis [15]. The subjective LS is, as expected, in the highest possible values for the contralateral knee, and in the high range after surgery and rehabilitation, since the amateur sportsmen reported quasi-normal competitive activities [9]. LS is lower when referred to the injured knee before surgery, also as expected. Table 1 shows there is little correlation between LS and TFCP migration, both as position within the plateau and as range of migration or loseness. The information conveyed by the two methods, LS and TFCP, is therefore independent one from the other, and one of them cannot be inferred from the other. Subjective questioning gives no information on the kinematics results of surgery, at least within the variability of the otherwise apparently successful interventions of the cases described here. Patients with high subjective LS (91\% to $100 \%$ ) show diverse results in terms of TFCP migration amplitude (17\% to $30 \%$ ) and positioning with respect to the tibial plateau (51\% to $62 \%)$.

It should be noted that these results are consequences of the fact that all five patients were submitted to successful surgical operations, confirmed by high subjective LS. The analysis of a wider diversity of outcomes, including sub optimal surgical results, may show less coincident LS figures to be paired with the variety of TFCP migration values. In such a setting of more diverse outcomes, the correlation between personal satisfaction and objective measurement may also prove true, and therefore clinically useful [32] for a wide variety of patients.

What the present series of patients suggests here is that the surgical results -knee articulation either tighter or with more laxity- do not account for the subjective evaluation by the patient. It looks as if patients are happy irrespective of the TFCP migration range, within the limits given here $(17 \%$ to $30 \%$ range and $51 \%$ to $62 \%$ starting point of TFCP migration to tibial plateau posterior border) following methods and nomenclature of Kellis [21]. Both subjective and objective evaluation are important to record $A C L$ reconstruction follow up.

Since normal kinematic movement of the knee articulation includes roll and glide to foster cartilage nutrition [22], the TFCP migration range must be considered. A knee with a reconstructed ACL with $20 \%$ TFCP movement must have less cartilage stimulation than a normal knee with $60 \%$ migration. This observation may turn into the starting point of future research on the clinical use TFCP migration and the impact it may have on long term evaluation of subcondral damage and subsequent arthrosis [33]. Irrespective of the short term subjective satisfaction of the five patients, their long term articular condition may differ depending on the more or less wide-area cartilage stimulation. A similar observation was published regarding changes in the kinematics of the knee joint due to $A C L$ rupture resulting in abnormal joint 
loads, which increased the risk of damage to the cartilage and the menisci [34].

In the short term, clinical practice -confirmed by our datastates that a limited TFCP range seems to have no importance for the patient and his reported comfort, because a $20 \%$ migrating knee behaves in very much the same way as a $60 \%$ TFCP migrating knee, both exhibiting normal kinematics. This fact is surprising, since one would expect that a limited TFCP glide distance would imply a smaller friction area between the articular surfaces. Smaller surface would be associated with higher stress and thus a premature impairment of contact areas and cartilage. With this idea in mind, our CINARTRO method could describe in the future different patterns of friction due to TFCP migration to be associated with different articular cartilage and menisci damage risk in the long term. This hypothesis is pending experimental evidence and subsequent data processing to support follow up strategies and monitoring.

What was initially a research hypothesis to develop an objective measurement of $A C L$ reconstruction, gave rise to a kinematic study of the knee. A simple procedure, CINARTRO $[4,35]$, was developed for clinical use. Concomitantly, the satisfaction of the five patients whose knees -injured and reconstructed- was evaluated as unanimously high with LS scores of $91 \%$ to $100 \%$. A preliminary conclusion of this work is that subjective self evaluation of $A C L$ reconstruction is not correlated with greater or smaller TFCP excursion within the knee articulation, at least within the limits of $25 \%$ to $42 \%$ (hanging) up to $50 \%$ to $62 \%$ (extension). Future research on $\mathrm{ACL}$ reconstructions with tighter results in terms of TFCP excursion along with probably sub optimal subjective evaluations will broaden the scope of surgical and rehabilitation outcomes to correlate. Another aspect to examine after longer periods of time $(5,10$ or 20 years) is the effect of shorter TFCP excursions -with consequently greater cartilage friction- on subjective evaluation of normal every day life activity and cartilage damage. The hypothesis of possible articular structural damage triggered by clinical situations perceived as normal in the short term (as analyzed in the present paper) follows the observations of Scarvell and co workers, still waiting for confirmation for more than a decade [36].

\section{Limitations}

The present research has the limitation of the number of subjects studied. Despite this fact, the methodology we suggest appears clearly feasible and reliable. More studies are needed nevertheless to estímate the usefulness as a follow up method in case of reconstructed ACL. A second limitation is the use of the Tibio-femoral Contact Point (TFCP) which is not the physical instantaneous rotating centre, but a point whose location is readily understood by clinicians. We are planning to add the real instantaneous mechanical rotating centre in future studies. The migration of the TFCP proved of limited utility to quantify the "tying" or "looseness" of the articulation, which is "per se" the basis for further research aimed at the inclusion of other features. The third limitation refers to the fact that we have studied here only the projection on a saggital plane, disregarding relevant axial tibial rotation. This limitation seems aceptable since we have developed a simple clinical appraisal procedure, with only one VFC exposition. This limitation is nevertheless not surprising since all usual clinical methods are also limited to the sagittal plane, in addition to being static tests such as the KT1000 or Lachmann procedures. Overall, the limitations of our work are compatible with its application in clinical practice.

\section{Competing interests}

The authors declare that they have no competing interests.

Authors' contributions

\begin{tabular}{|l|c|c|c|}
\hline Authors' contributions & DS & FM & FS \\
\hline Research concept and design & $\checkmark$ & -- & $\checkmark$ \\
\hline Collection and/or assembly of data & $\checkmark$ & -- & -- \\
\hline Data analysis and interpretation & $\checkmark$ & $\checkmark$ & $\checkmark$ \\
\hline Writing the article & $\checkmark$ & $\checkmark$ & $\checkmark$ \\
\hline Critical revision of the article & $\checkmark$ & $\checkmark$ & $\checkmark$ \\
\hline Final approval of article & $\checkmark$ & -- & $\checkmark$ \\
\hline Statistical analysis & $\checkmark$ & $\checkmark$ & -- \\
\hline
\end{tabular}

\section{Acknowledgement}

The authors thank Luis Francescoli M.D., surgeon who operated on the patients whose data are shown in the present article, for motivation and guidance.

Publication history

Editor: Gordon John Alderink, Grand Valley State University, USA. Received: 03-Sep-2015 Final Revised: 14-Oct-2015

Accepted: 23-Oct-2015 Published: 03-Nov-2015

\section{References}

1. Gawel J, Fibiger W, Starowicz A and Szwarczyk W. Early assessment of knee function and quality of life in patients after total knee replacement. Ortop Traumatol Rehabil. 2010; 12:329-37. I Article I PubMed

2. Majewski M, Susanne $H$ and Klaus S. Epidemiology of athletic knee injuries: A 10-year study. Knee. 2006; 13:184-8. I Article I PubMed

3. Griffin LY, Agel J, Albohm MJ, Arendt EA, Dick RW, Garrett WE, Garrick JG, Hewett TE, Huston $L$ and Ireland ML et al. Noncontact anterior cruciate ligament injuries: risk factors and prevention strategies. J Am Acad Orthop Surg. 2000; 8:141-50. | Article | PubMed

4. F Simini, D Santos and L Francescoli. Videofluoroscopy Instrument to Identify the Tibiofemoral Contact Point Migration for Anterior Cruciate Ligament Reconstruction Follow-up: CINARTRO. IOP Conference Series, in press, 2015 SABI San Nicolàs, Argentina. 2015.

5. Lewis PB, Parameswaran AD, Rue JP and Bach BR, Jr. Systematic review of single-bundle anterior cruciate ligament reconstruction outcomes: a baseline assessment for consideration of double-bundle techniques. Am J Sports Med. 2008; 36:2028-36. I Article I PubMed

6. Herrington L, Wrapson C, Matthews M and Matthews H. Anterior cruciate ligament reconstruction, hamstring versus bone-patella tendon-bone grafts: a systematic literature review of outcome from surgery. Knee. 2005; 12:41-50. | Article | PubMed Abstract | PubMed Full Text

7. Griffin LY, Agel J, Albohm MJ, Arendt EA, Dick RW, Garrett WE, Garrick JG, Hewett TE, Huston L, Ireland ML, Johnson RJ, Kibler WB, Lephart S, Lewis JL, Lindenfeld TN, Mandelbaum BR, Marchak P, Teitz CC and Wojtys 
Santos et al. Physical Therapy and Rehabilitation 2015,

EM. Noncontact anterior cruciate ligament injuries: risk factors and prevention strategies. J Am Acad Orthop Surg. 2000; 8:141-50. | Article I PubMed

8. Berchuck M, Andriacchi TP, Bach BR and Reider B. Gait adaptations by patients who have a deficient anterior cruciate ligament. J Bone Joint Surg Am. 1990; 72:871-7. | Article | PubMed

9. Micheo W, Hernandez $L$ and Seda C. Evaluation, management, rehabilitation, and prevention of anterior cruciate ligament injury: current concepts. PM R. 2010; 2:935-44. | Article | PubMed

10. Micheo W, Hernandez $L$ and Seda C. Evaluation, management, rehabilitation, and prevention of anterior cruciate ligament injury: current concepts. PM R. 2010; 2:935-44. | Article | PubMed

11. Imbert $P$, Belvedere $C$ and Leardini $A$. Human knee laxity in ACL-deficient and physiological contralateral joints: intra-operative measurements using a navigation system. Biomed Eng Online. 2014; 13:86. | Article | PubMed Abstract | PubMed Full Text

12. Imbert $P$, Belvedere $C$ and Leardini $A$. Human knee laxity in $A C L-d e f i c i e n t$ and physiological contralateral joints: intra-operative measurements using a navigation system. Biomed Eng Online. 2014; 13:86. | Article | PubMed Abstract | PubMed Full Text

13. Baltzopoulos V. A videofluoroscopy method for optical distortion correction and measurement of knee-joint kinematics. Clin Biomech (Bristol, Avon). 1995; 10:85-92. | Article | PubMed

14. Tsaopoulos DE, Baltzopoulos V and Maganaris CN. Human patellar tendon moment arm length: measurement considerations and clinical implications for joint loading assessment. Clin Biomech (Bristol, Avon). 2006; 21:657-67. | Article | PubMed

15. Dennis DA, Mahfouz MR, Komistek RD and Hoff W. In vivo determination of normal and anterior cruciate ligament-deficient knee kinematics. $J$ Biomech. 2005; 38:241-53. | Article | PubMed

16. Johnson DS and Smith RB. Outcome measurement in the ACL deficient knee--what's the score? Knee. 2001; 8:51-7. | Article | PubMed

17. Swanenburg J, Koch PP, Meier $\mathrm{N}$ and Wirth B. Function and activity in patients with knee arthroplasty: validity and reliability of a German version of the Lysholm Score and the Tegner Activity Scale. Swiss Med Wkly. 2014; 144:w13976. | Article | PubMed

18. Briggs KK, Steadman JR, Hay CJ and Hines SL. Lysholm score and Tegner activity level in individuals with normal knees. Am J Sports Med. 2009; 37:898-901. | Article | PubMed

19. Lysholm J and Gillquist J. Evaluation of knee ligament surgery results with special emphasis on use of a scoring scale. Am J Sports Med. 1982; 10:150-4. | Article | PubMed

20. Tegner $Y$ and Lysholm J. Rating systems in the evaluation of knee ligament injuries. Clin Orthop Relat Res. 1985; 43-9. | Article | PubMed

21. Kellis $E$ and Baltzopoulos V. In vivo determination of the patella tendon and hamstrings moment arms in adult males using videofluoroscopy during submaximal knee extension and flexion. Clin Biomech (Bristol, Avon). 1999; 14:118-24. | Article I PubMed

22. Scarvell JM, Smith PN, Refshauge KM, Galloway H and Woods K. Comparison of kinematics in the healthy and $A C L$ injured knee using MRI. J Biomech. 2005; 38:255-62. | Article | PubMed

23. D. Santos and G. Fabrica. Directrices Biomecánicas para el Entrenamiento Isométrico de Cuadriceps durante la Rehabilitación del Ligamento Cruzado Anterior (LCA). Rev. Iberoam. Fisioter. y Kinesiol. 2002; 5:101-108. | Website

24. Risberg MA, Holm I, Steen $H$ and Beynnon BD. Sensitivity to changes over time for the IKDC form, the Lysholm score, and the Cincinnati knee score. A prospective study of $120 \mathrm{ACL}$ reconstructed patients with a 2-year follow-up. Knee Surg Sports Traumatol Arthrosc. 1999; 7:152-9. I Article | PubMed

25. Marx RG, Jones EC, Allen AA, Altchek DW, O'Brien SJ, Rodeo SA, Williams RJ, Warren RF and Wickiewicz TL. Reliability, validity, and responsiveness of four knee outcome scales for athletic patients. J Bone Joint Surg Am. 2001; 83-A:1459-69. | Article | PubMed

26. Marx RG. Knee rating scales. Arthroscopy. 2003; 19:1103-8. | Article | PubMed
27. C. Bernardes, J. Cañeiro, P. Matos, D. Mauro, Aldabe, L. F. Silveira, M. Araújo and J. LOSS. Determinação de Parâmetros Biomecânicos para o Modelamento da Articulação do Joelho. Anais do XI Congresso Brasileiro de Biomecânica. 2005. | Pdf

28. C. Bernardes, J. P. Cañeiro, L. Tartaruga, L. F. Silveira, M. Araújo and J. Loss. Objetividade e Fidedignidade do Processo de Digitalização Manual de Imagens de Videofluoroscopia. Anais do XI Congresso Brasileiro de Biomecânica. 2005. | Pdf

29. Baltzopoulos V. A videofluoroscopy method for optical distortion correction and measurement of knee-joint kinematics. Clin Biomech (Bristol, Avon). 1995; 10:85-92. | Article | PubMed

30. D. Santos. Estudio de los Centros de Rotación Instantáneos de la Rodilla en Pacientes con Plastia del Ligamento Cruzado Anterior. Tesis de maestría en Ciencias Médicas; PROINBIO, Universidad de la República. Montevideo. 2014. | Article

31. J. Maritz. Distribution-Free Statistical Methods. London: Chapman and Hall. 1981.

32. L. Herrington. The rehabilitation of two patients with functionally unstable ACL deficient knees: a case report. Phys. Ther. Sport. 2004; 5:175-178. | Article

33. D. Santos, F. Simini, L. Francescoli, F. Massa, A. Barquet and T. Camarot. Beyond traditional clinical evaluation of knee articulation movement to physiological assesment of dynamic ACL funtion during extension. XIII International Symposium on 3D Analysis of Human Movement. École Polytechnique Fédérale de Lausanne; Switzerland. 2014. I Pdf

34. Brandsson S, Karlsson J, Eriksson BI and Karrholm J. Kinematics after tear in the anterior cruciate ligament: dynamic bilateral radiostereometric studies in 11 patients. Acta Orthop Scand. 2001; 72:372-8. | PubMed

35. F. Simini and D. Santos. Anterior Cruciate Ligament Reconstruction Follow-up Instrumentation based on Centre of Rotation Videofluoroscopy Determination: Development of an original equipment, CINARTRO, and first clinical use. IEEE Conf. proceedings- Int. Instrum. Meas. Technol. I2MTC. 2014. | Article

36. Scarvell JM, Smith PN, Refshauge KM, Galloway HR and Woods KR. Does anterior cruciate ligament reconstruction restore normal knee kinematics?: A prospective MRI analysis over two years. J Bone Joint Surg Br. 2006; 88:324-30. | Article | PubMed

\section{Citation:}

Santos D, Massa F and Simini F. Evaluation of anterior cruciate ligament reconstructed patients should include both self-evaluation and anteroposterior joint movement estimation? Phys Ther Rehabil. 2015; 2:3. http://dx.doi.org/10.7243/2055-2386-2-3 